Ralf Walkenhaus

Konservatives

Staatsdenken 

Ralf Walkenhaus

\section{Konservatives Staatsdenken}

Eine wissenssoziologische Studie zu Ernst Rudolf Huber

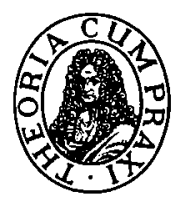

Akademie Verlag 
Die Deutsche Bibliothek - CIP-Einheitsaufnahme

\section{Walkenhaus, Ralf:}

Konservatives Staatsdenken : eine wissenssoziologische Studie

zu Ernst Rudolf Huber / Ralf Walkenhaus. - Berlin : Akad. Verl., 1997

Zugl.: Bochum, Univ., Diss., 1993

ISBN 3-05-003040-2

(C) Akademie Verlag GmbH, Berlin 1997

Der Akademie Verlag ist ein Unternehmen der VCH-Verlagsgruppe.

Gedruckt auf chlorfrei gebleichtem Papier.

Das eingesetzte Papier entspricht der amerikanischen Norm ANSI Z.39.48 - 1984

bzw. der europäischen Norm ISO TC 46.

Alle Rechte, insbesondere die der Übersetzung in andere Sprachen, vorbehalten. Kein Teil dieses Buches darf ohne schriftliche Genehmigung des Verlages in irgendeiner Form - durch Photokopie, Mikroverfilmung oder irgendein anderes Verfahren - reproduziert oder in eine von Maschinen, insbesondere von Datenverarbeitungsmaschinen, verwendbare Sprache übertragen oder übersetzt werden.

Druck: GAM Media GmbH, Berlin

Bindung: Verlagsbuchbinderei Mikolai GmbH, Berlin

Printed in the Federal Republic of Germany 